\title{
Journal of Aging and Health
}

\section{An age old problem? Estimating the impact of dementia on past human populations}

\begin{tabular}{|r|l|}
\hline Journal: & Journal of Aging and Health \\
\hline Manuscript ID & JAH-15-302.R1 \\
\hline Manuscript Type: & Original Article \\
\hline Keywords: & active life expectancy, dementia, demography, epidemiology, history \\
\hline Abstract: & $\begin{array}{l}\text { Objectives: To model the impact of dementia on past societies. Methods: } \\
\text { We consider multople lines of evidence indicating elderly individuals to } \\
\text { have been more common throughout the past than is frequently accepted. } \\
\text { We then apply known dementia incidence/ prevalence rates to plausible } \\
\text { assumptions of past population structures to suggest prevalence in the } \\
\text { past. Results: Dementia prevalence in pre-modern societies is likely to } \\
\text { have been around 5\% of the rate seen in modern, developed countries, but } \\
\text { with a total past incidence running into billions. Discussion: Dementia is } \\
\text { often seen as a 'modern' challenge which humans have not had to contend } \\
\text { with before. We argue that this condition has had considerably greater } \\
\text { effects than previously envisaged and is a challenge that humans have } \\
\text { already withstood successfully, on one hand at a lower incidence but on the } \\
\text { other without the considerable clinical, technological and social advances } \\
\text { that have been made in recent times. }\end{array}$ \\
\hline
\end{tabular}




\section{An age old problem? Estimating the impact of dementia on past human populations}

\section{Introduction}

The cumulative effects of advances in medicine, sanitation and diets seen in the developed world over the last two centuries are a well-rehearsed story. First infectious diseases that previously resulted in frequent and sustained high mortality rates were effectively eradicated, followed more recently by lifestyle changes which reduced the risks of the cardiovascular and pulmonary diseases that came in their wake. As a result affluent regions are now characterised by populations with growing susceptibility to chronic conditions associated with ageing. As a category of disease that is incurable and which commonly increases in incidence with advancing age dementia is just such a condition. Whilst dementia is not considered part of the 'normal' aging process, it does mainly affect older individuals $(65+)$ (Alzheimer's Disease International, 2014). and a broad range of studies are in general agreement that the likelihood of developing the condition advances on a logarithmic scale, doubling approximately every five years from the age of 65 (Ritchie et al., 1992; Ritchie \& Kildea, 1995; Brookmeyer et al., 2011; Rocca et al., 2011). The term 'incidence' indicates the likelihood that an individual in a defined population will acquire a particular condition during a given period of time. The term 'prevalence' then refers to the count or proportion of persons who currently have that disease at a given point in time. Prevalence therefore conveys information about the overall impact in terms of care and associated services that the condition places on society in general. With regard to dementia Brookmeyer et al. $(2011,61)$ point out that as dementias are "relatively common, have relatively long duration, and lead to marked impairment in social and occupational functioning, their burden level is high". The current UK prevalence of dementia among people aged $>65$ is $7.1 \%$ (Alzheimer's Society, 2014). It was estimated that by 2015 there will be 850,000 people with dementia representing $1.32 \%$ of the total population. The current financial burden of UK dementia care is estimated $£ 26.3 \mathrm{bn}$ p.a. (Alzheimer’s Society 2014). Global estimates produce a similar picture. Global annual incidence is almost 7.7 million, with global prevalence in 2010 estimated at 35.6 million. The worldwide costs of dementia were assessed to be US\$604 billion in 2010 (WHO 2012). 
Dementia is an umbrella term used to describe a wide range of conditions all of which affect cognition and result in cognitive impairment. The realization that dementia is becoming an increasingly significant issue among developed countries as average life span increases has prompted a growing number of both regional and global studies estimating the overall disease impact (examples include: Ferri et al. 2005; Kalaria et al. 2008; Henderson \& Broe, 2010; Brookmeyer et al., 2011; Catindig et al., 2012; Gènova-Maleras et al., 2012). More recently such studies have tended towards making hypothetical projections regarding how prevalence and the associated impact on society is likely to develop in the future (Brookmeyer et al., 2007, Colantuoni et al., 2010; Banerjee, 2012). Whilst precise methods vary, such studies commonly operate on the principle of estimating future prevalence by forward calculation from age specific incidence rates and survival figures in relation to projected population size. UK dementia prevalence is projected to rise to over 1 million by 2025 and to exceed 2 million by 2051, assuming age specific incidence remains stable (Alzheimer's Society 2014). Similarly the global figure is projected to almost double every 20 years to 65.7 million in 2030 and 115.4 million in 2050 (WHO 2012). A common thread running through such studies is the implicit notion that degenerative conditions associated with old age are amongst a raft of 'modern' challenges that humans have not previously had to contend with in any significant way. Such a view rests on the commonly held assumption that few people in the past survived to what is now regarded as 'old age'. In the current article we consider several lines of evidence to the contrary which suggest that elderly individuals were more common throughout the human past than is frequently accepted. On this basis we take the principle of predicting prevalence in a novel direction. Given that the current incidence and prevalence of dementia are relatively well documented at least in developed regions, it may also be possible to make suggestions regarding the likely extent of prevalence in the past. By back calculating the likely size and age structure of past populations it should be possible to make some broad but plausible general suggestions regarding the overall order of magnitude of the likely numbers of people affected over time, which we argue is likely to have been considerably greater than previously envisaged. There are many forms of dementia, including early onset dementia which is said to affect between $2-10 \%$ of all cases of those under the age of 65 years (Alzheimer Disease International, 2014). Given the focus of the current article with regards to ageing in the past, we have 
concentrated specifically on dementia which affects older people (65+) and excluded early-onset dementia from the present study. Whilst the rate of progression in these conditions is variable (Storandt et al., 2002; Mitchell \& Shiri-Feski, 2009) the general trajectory of cognitive decline is characterised by stages that are progressive and broadly predictable.

\section{Longevity and in the Past}

There is broad acceptance of the idea that human life expectancy in developed regions is currently greater than it has ever been (Blagosklonny, 2010; Marsh, 2014, Moody \& Saunders, 2014, 301) with a general consensus that in the past people usually died at an earlier age than is common in many parts of the world today. However, notions regarding the actual age people might expect to have lived to at any given time in the past are commonly vague and rarely substantiated by concrete data. In attempting to produce estimates for the likely age structure of past populations several lines of evidence are available, these are contemporary written sources, age determinations obtained from excavated archaeological burials and ethnographic observations of the age structure of recent preindustrial populations.

\section{Written sources}

The idea that in the past few people survived into what we would now call 'old age' is a recurrent theme in the popular imagination. For example, in describing the Anglo-Saxon period Lacey \& Danziger $(1999,10)$ state "most adults died in their forties, and fifty year olds were considered venerable indeed" although they provide no evidence to substantiate this claim. In a similar vein Scott $(2010,10)$ states that according to a "reliable source... in the early $14^{\text {th }}$ century, life expectancy at birth may have been as low as 25 ". Such views derive largely from misinterpretations of the concept of "average life expectancy at birth" (Metzler, 2013, 96; Cave \& Oxenham, 2014). Here the mean age attained -which by definition will normally be superceded by a substantive portion of the populationis misread as a modal average, i.e. the age at which most people might be expected to die. However, various commentaries by ancient and medieval authors and contemporaneous records provide evidence to the contrary. However, a broad range of commentaries by ancient and medieval authors 
and contemporaneous records provide evidence to the contrary (See Appendix 1.1). During the classical period (500BC - AD500) individuals from throughout the Greek and Roman world are repeatedly recorded as having reached ages beyond 60 and even beyond 90. Law codes and administrative documents similarly make common reference to older individuals making it clear that survival to such ages was not uncommon. The same is true for the Medieval period where again reaching older age was clearly regarded as unremarkable even if less common than today.

\section{'Dead populations' - evidence from archaeological burials}

With regard to past population structure the only direct source of evidence available is the remains of past people themselves, usually in the form of skeletal material excavated from archaeological cemeteries and other burial locations. In considering evidence from human burials Chamberlain $(2000,104)$ argues that "there are strong grounds for reasoning that human populations in the past had similar age structures to those documented in the present day". Whilst documentary sources of evidence regarding past populations are progressively more biased, incomplete and unrepresentative of the overall population with increasing distance from the present, archaeological data are less subject to such limitations. On reviewing the picture of past societal age structures provided by skeletal populations one might initially conclude that the sort of view cited above, whereby few people in the past survived into old age, must be correct. Individuals in younger age categories are well represented, as are those living up to around 50. However, due to limitations in the precision of methods for determining age-at-death from the skeleton, older individuals (i.e $>55 \mathrm{yrs)} \mathrm{often} \mathrm{appear}$ under-represented. Due to differences in the rates at which the skeletons of different individuals deteriorate as they age it is difficult to differentiate between a 60 year old and an 80 year old from their skeleton. Osteologists tend to err on the side of caution and accordingly any proportion of a population to have reached advanced ages ( 70 and beyond) will be masked in such a dataset (Figure $1)$.

Essentially then, age determination in skeletal remains is subject to biases that tend to systematically under-estimate the age of older individuals (Waldron, 1994, 2007, Cave \& Oxenham, 2014). 
However, Chamberlain (2000) has demonstrated that such biases can be overcome by taking a Bayesian approach based on known error rates in skeletal ageing techniques, arrived at by applying those techniques to the skeletons of modern individuals whose age-at-death was documented. By employing such an approach the proportions of a sample assessed as being within each skeletal age category (20-35 yrs, 35-55 yrs, 55+ yrs) can be corrected for systematic bias. He further demonstrates that when such corrected profiles are compared with both model life table data for similar censused populations and documentary burial records (for the same cemetery) a similar characteristic U-shaped mortality profile is produced (Figure 2). A similar position is taken by Waldron (1994, 16-20) who notes that the age distribution of a dead population from a developing country is typically U-shaped with most deaths occurring at both extremes of the age range. As economic conditions improve the number of deaths in the young tends to reduce, shifting the distribution to the right. Given that archaeology effectively offers us a window onto various 'developing countries' be they Roman Britain or Pre-Columbian Peru it is reasonable to expect the populations of such societies to resemble those of modern under-developed or developing countries rather than unsubstantiated notions of societies where the elderly were largely absent. These points are further supported by a range of other archaeological studies (see Appendix 1.2).

\section{A window to the past? The ethnographic present}

A further strand of evidence useful in assessing past longevity is the analysis of ethnographically studied living populations who pursue ways of living commensurate those of past societies. With regard to such evidence Gurven and Kaplan's (2007) study of life expectancy among hunter-gatherers constitutes an important resource in that it is both rigorous in its approach and also it utilises an unparalleled sample of data that are unlikely to become available again as such peoples rapidly become acculturated by contact with more developed societies. In considering only securely documented populations Gurven and Kaplan demonstrate that survivorship into later life among such groups is not uncommon with an average of $20 \%$ survival past 65 years (l65) among hunter gatherers, $19 \%$ in forager-horticulturalists and 34\% among acculturated hunter-gatherers (this latter 
being groups who have begun to be influenced by aspects of developed societies). These figures compare interestingly with censused data from $18^{\text {th }}$ century Sweden where $165=20 \%$ (Gurven and Kaplan, 2007, 321). Further, most of the variation between the mortality profiles and respective life expectancy of past populations as compared to those of populations in modern developed countries are accounted for by differences in the infant and child mortality rates with survival into older age categories contributing much less to the overall differences (Gurven \& Kaplan, 2007, 330). This point is also supported by Chamberlain (2000) who compares modern censused hunter gatherer groups with a range of farming groups from the $16^{\text {th }}$ to $20^{\text {th }}$ centuries. The 165 figure ranges from 20$35 \%$ in the hunter-gatherer groups and $20-38 \%$ among the farming groups. Gurven and Kaplan's (2007) study prompts important conclusions regarding humans in general, as they conclude that there is a "characteristic life span for our species" whereby human beings have developed to function for about seven decades in the environment in which our species evolved "before which time humans remain vigorous producers and after which senescence rapidly occurs and people die". The mean modal age at death among hunter-gatherer groups in this study was 72 with a range of 68-78 years which they argue to essentially be the "adaptive human life span". This adaptive estimate prompts the conclusion that many published assessments of prehistoric life expectancy must be incorrect (see Appendix 1.3).

\section{Dementia in the historical record}

Given, the frequency with which past people are likely to have lived past what would now be regarded as retirement age it is unsurprising to also find mentions of age related disorders and particularly of dementia. The earliest reference to dementia symptoms in an older individual is an Egyptian text dating from the $24^{\text {th }}$ century BC (Karenberg \& Förstl, 2006, 7). Again references to dementia in the elderly both in literary and administrative documents are known from the throughout the classical period, whilst references by Chaucer and Shakespeare (Ottilingham, 2007) demonstrate that dementia in older people was clearly recognised in the Medieval and Early Modern periods (see Appendix 2). The presence of people with dementia in Western societies comes into view more clearly in the post-Medieval period as such individuals came to be incarcerated in formal institutions, 
initially prisons and later asylums, although there may have been little functional difference between the two for those interned within (Porter, 1999, 495).

\section{Summary}

In summary, there are three independent lines of evidence which prompt similar conclusions that the proportion of people surviving into old age in the past has been frequently underestimated. Whilst, there is no doubt that greater proportions of people now reach an advanced age than ever before, we otherwise have secure reasons to think the past was essentially like the present in that old age was not in itself uncommon. Furthermore, written records attest the existence of enough older individuals who had developed dementia that it was a state both generally recognised and considered worth commenting upon.

\section{Care in the past}

The actual prevalence of a debilitating condition will depend strongly on people's willingness and ability to provide care and support for affected individuals. With regard to dementia this raises the question of at what point it became viable to care for infirm elderly individuals during the past? Before the transition to farming and herding, humans lived in small, mobile bands subsisting by hunting and gathering. On one hand there are a range of well documented cases of prehistoric individuals that must have been cared for by others in order to keep them alive, some of which predate settled ways of living (Trinkaus \& Zimmerman, 1982; Dickel \& Doran, 1989; Schutkowski et al., 1996; Hawkey, 1998; Luna et al. 2008; Tilley \& Oxenham, 2011; Tilley, 2013 -also see Figure 1b). However, these examples all involve physical infirmity and still leave the question of how long a small mobile group could look after a demented individual with a tendency to wander, lacking capacity for self-care and unable to make positive contributions to group survival. In such circumstances it seems unlikely that an individual with dementia could expect to survive without assistance for any significant period as the disease progressed. In this respect the switch to domesticated resources, with its new emphasis on settled ways of living and increasing group sizes is 
argued to take on further importance as the point at which human communities first gained the capacity to care for mentally infirm individuals in a sustainable manner (see supplementary material).

\section{Methods \\ Pathology by numbers? Modelling past disease prevalence}

In order to produce a model of past disease prevalence, reasonable estimates are required for two sets of variables, firstly the structure of past human populations with regard to age at death and secondly the extent to which disease incidence and subsequent survival times might have differed in the past. Regarding the former, data for the construction of a general model of past population structures were obtained from Coale \& Demeny's (1983) level five model west life tables. These have been shown in previous palaeodemographic studies to be useful for modelling pre-industrial population structures (Chamberlain 2000, 103). Given the broad-scale of the current study we have taken account of intrinsic factors, such as birth and death rates, however extrinsic factors such as migration have been excluded. While migration no doubt played a significant part in past human history, given the aggregate nature of the current study its effects are likely to have been minimal in relation to the question being considered. Also migration tends to impact younger-adult individuals moving in and out of societies and so its effects on those affected by dementia would be further limited. The model life table data were therefore used to construct a set of equations to simulate the development of a closed population over time given a specific birth rate and age specific mortality rates for a settled, agricultural pre-industrial population. Here a series of algorithms developed by the second author as part of a wider doctoral project were applied (Table 1). These algorithms made it possible to progress this static life table, to one that could be advanced in five-year intervals (to give cohorts within predetermined age categories) to predict population size and age structure from a given initial population (e.g. 10,000) over any given period of time (e.g. 50 years, 500 years, etc.)

In order to account for the estimated growth rate in pre-industrial populations, a birth rate of 4.0 was applied, i.e four live births per annum per 1000 members of the population, which within the 
simulations produced a $0.5 \%$ increase annually $(r)$. Over time this results in exponential growth, which can be seen in the short-term in populations in the pre-industrial era. For example such growth occurred during the stable and prosperous conditions experienced in Europe between 1100-1350, only to be temporarily arrested by the Black Death (Gottfried, 1983, 16-22). Over the short term such mortality crises, such as the Black Death, can have dramatic effects on population structures. However, again over an extended period, as in the current model intended to cover a period of several millennia, the effects of such events will ultimately be minimal (or at least indistinguishable on such a large scale) in the long term.

A further parameter was then applied to the simulation $k(x)$, which represented the age-specific probability of being affected by dementia. In all age categories below 59 years this probability was zero. In all age categories from 60-64 years and above this probability was determined by the modern age specific incidence rates as listed in Table 1 and Table 2 . In order to avoid the over-estimation of those living with dementia, the mortality rate for each age interval cohort above 60-64 was divided between affected and non-affected individuals. When a cohort progressed to the next age interval category, affected individuals were excluded from those who were at risk of acquiring it within this category. This made it possible to produce an overall incidence rate in a given period taking account of the total population structure.

\section{Size and structure of past populations: how many people have ever lived?}

In order to estimate the general impact of a given disease with a known incidence during the past it is necessary to have a plausible estimate for the respective size of the population considered over a given time, in addition to its structure. In the case of the current project, following the principle used to make forward global dementia projections we aimed to estimate the incidence and prevalence of dementia retrospectively at a global level by applying the incidence rates and population structure derived from the above model to past global population estimates over time.

A wide range of published estimates for the overall size of the global population at differing times in human history are in broad agreement as to the general trajectory of the growth the human species. 
Essentially for much of the time modern humans have existed during the last $100-200,000$ years, growth in population numbers will have been relatively stable increasing only very slowly, with radical step-changes occurring at two points. These were the Neolithic Demographic Transition (NDT) and the Industrial Revolution through which we are still living now. For the latter part of human history population size has since assumed an accelerating rate of exponential growth. Figure 3 illustrates this point by combining a range of published estimates to produce an aggregate view with an upper limit, lower limit and median point drawn as curves spanning the last 10,000 years. For the purpose of the current study we have used figures produced by the demographer Carl Haub (2011) for the Population Reference Bureau, Washington. These are broadly accepted internationally, have been subject to repeated revision by the UN and they also correspond well with the median figures from the aggregated curves in Figure 3 so can be taken as a reasonable representation of current thinking on the course of past world population growth. One criticism of Haub's (2011) figures however, is that they gloss over a large portion of prehistory going from $50,000 \mathrm{BC}$ to $8,000 \mathrm{BC}$ in one tranche and then $8,000 \mathrm{BC}$ to $\mathrm{AD} 1$ in a second. Whilst the population figures given at the beginning and end points of these sections are entirely plausible the trajectory of change within them is masked. There is general agreement that prior to the birth of agriculture world population is likely to have been essentially stable at a few million forager/ hunters (estimates vary from 2-3 million at the lower end to 10 million at most at the high end). A figure of 5 million is a reasonable estimate, but the salient point is that this will have begun to change with accelerating speed following the appearance of agriculture so most of the demographic change between $8,000 \mathrm{BC}$ and $\mathrm{AD} 1$ will have happened more towards the end of this period and not as a steady linear expansion. A further reason for using Haub's (2011) figures is that they are based on a mathematical model that takes account of population size, birth rates and death rates and which comes to its own conclusions in a transparent manner. Haub (2011) estimates the total number of human beings to have ever been born to be just under 108 billion although this largely reflects high birth rates coupled with high infant/child mortality and nothing like this number were ever alive at any one time.

Modelling 'Real World' Incidence and Prevalence 
As above we have made the assumption that societies consisting of small mobile bands of foragers and hunters would not be able to sustain/care for a person with dementia for any extended period or in significant numbers, so such groups were excluded from the current project. Consequently, the estimates here only consider human populations since the adoption of agriculture. To arrive at a reasonable estimate for the remaining population we would need to decide the likely incidence of dementia in a pre-industrial population. As stated the model developed above takes model life table data for pre-industrial populations and then applies the age-specific dementia incidence rates for modern populations. This latter is an obvious point where the model could be criticised as incidence of the disease in past populations could have differed. A plausible avenue to explore this point is in the extent of dementia in modern developing countries. Certainly, there is general agreement that late onset dementia is not a phenomenon specific to developed nations. Older people with dementia are found in every world region today (Kalaria et al. 2008), whilst Catindig et al. (2011) estimate that $60 \%$ of all people with dementia live in developing countries. However, studies conducted on developing countries are often contradictory. Some give a lower age-specific incidence of dementia than developed countries for example Catindig et al.'s (2011) meta-analysis found a high degree of variation across Asian countries but others, for example Aboriginal Australians (Henderson \& Broe, 2010) have been recorded to have a higher rate. Kalaria et al. (2008) and Ferri et al. (2005) undertook general international meta-analyses and both found widely differing prevalence rates among developing countries with generally lower but some higher rates than developed regions. The source of such variations may lie in genetic or environmental factors. The latter is particularly likely for some populations, for example levels of smoking, diabetes, hypertension and other chronic conditions are high among aboriginal Australians and are likely to have an elevating effect on modern rates of dementia in comparison to levels prior to European contact (Smith et al. 2010). However other sources of variation may derive from methodological differences between studies (Catindig et al., 2011) and /or cultural differences where signs of dementia may often be regarded as normal aspects of ageing and are therefore going undiagnosed (Kalaria et al., 2008). As it is not currently possible to produce an agreed estimate for 'general' levels of dementia incidence among pre-industrial societies we have applied modern age-specific global dementia rates (Table 2) for the purpose of the current 
study, but would welcome revision of the results should more appropriate rates be defined in the future.

When the model was run over sufficient iterations to simulate 75 years ( 15 iterations of 5 year intervals) using the model life table data for preindustrial populations the proportion of the total population which developed dementia was $1.81 \%$. The current lifetime incidence rate for developed countries is in the region of $32.8 \%$ for men and $45 \%$ for women over 65 (Seshadri et al., 1997). Given that around $16 \%$ of people in developed countries will die before 65 (Office for National Statistics, 2007) this then gives a mean population lifetime incidence of $32.68 \%$ (hence the current level of public attention being given to dementia). Therefore, the results of our model suggest that due to higher levels of mortality and fewer people surviving to the relevant ages lifetime incidence in preindustrial populations was likely to have been only about $1 / 18^{\text {th }}(5.53 \%)$ of that seen in modern developed countries. The principal reason for this difference obviously lies in the much greater levels of infant and child mortality in pre-industrial populations, coupled with a lower mean age at death in those that survived their early years. In our model $71.87 \%$ of people born did not live beyond 65 years and so were never susceptible to dementia at the threshold set. When lifetime incidence is recalculated only for those living beyond 65 the figure obtained was $5.42 \%$ (approximately $1 / 6^{\text {th }}$ or $16.5 \%$ of the rate in modern populations). This latter difference rather reflects the lower proportion of over 65 year olds in pre-industrial societies reaching the advanced ages beyond 75 that are now extremely common in developed countries after which point dementia incidence rises sharply. Overall, the rates produced by the model then seem like reasonable and conservative estimates and could be argued to more likely underestimate than overestimate the actual incidence.

In order to estimate the impact of dementia on the whole of humanity's recent history the next stage was to take the global population at any given date and then decide what proportion of the world's population at that time are likely to have been 1.mobile foragers, 2 .settled farmers/pre-industrial and 3. 'modern' developed societies. This is obviously a gross simplification, but we would argue that given the likely margins for error in an exercise of this nature, any finer divisions would be unlikely to increase the overall accuracy. Before agriculture $100 \%$ of the world's population were foragers with 
an effective dementia prevalence close to zero (in that such groups could not sustainably care for someone with such a condition). Taking the view that this population was stable at approximately 5 million, any population increase above this must relate to the population explosion of the Neolithic Demographic Transition (NDT). We have therefore simply excluded the first 5 million individuals from this point onwards with the assumption that everyone else must now be settled farmers and so subject to the lifetime dementia incidence in our model of $1.81 \%$. As such, this rate has then been applied to most of the people who have ever lived.

A further broad division was then inserted that post 1900 in 'developed' countries, diets, sanitation and health care had become sufficiently improved to permit survival rates more closely approximating those that are seen now. The subsequent ageing populations would therefore be subject to an increase in dementia incidence as now seen in developed countries. The elderly population that has been subject to dementia in recent decades were those born in the early part of the $20^{\text {th }}$ century so this assumption is arguably realistic. The proportion of world population accounted for by developed countries declined from 29\% in 1900 to $15 \%$ in our own time (UN Population Division, 1999). This change is the result of the population boom in Europe and N. America etc. in the $18^{\text {th }}-19^{\text {th }}$ centuries (and briefly post 1945 ) then followed by declining birth rates in the $20^{\text {th }}$ century plus a corresponding population boom still ongoing in developing countries where most of the world's births now take place.

\section{Results}

The above divisions then allowed a modified dementia incidence rate to be produced that takes into account the proportions of the three societal types at each date range to give an incidence number for all the live births in each range (Table 3). These are then added together to give an overall figure for the global population since the birth of agriculture, the result of which is: $2,624,317,929$. At over two and a half billion this may appear to be a staggeringly high figure but in fact represents only $2.44 \%$ of the total population who have ever lived. Further if we then consider how many individuals were living with the disease at any one time this involves taking the survival time into account for those with the condition. Studies estimating future dementia prevalence work on the principle that length of 
survival is also modified by the risk of dying from another cause (competing risks) (Brookmeyer et al., 2011). People living with dementia in modern times can live for 10 years (or more) with the condition but the current average survival time is 4.5 years (Xie et al., 2008). By assuming a lower average survival time due to greater competing risks in pre-industrial populations we might suggest how many individuals might have been alive at any one time with the condition. This would give a prevalence rate to go with the life time incidence rate (Table 4). By taking the length of each period (8000 years for 8000BC to AD1, 100 years for AD1600-1700 etc) and dividing the total incidence by the number of years we arrive at an average incidence per year. If this is multiplied by the survival time we then get a prevalence figure -i.e. how many actually living with the condition at any one time. We have done this with a low and higher estimate for pre-industrial survival times (2 years and 3 years respectively), and with a slightly lowered overall rate for the recent periods to take account of developing countries). When calculated in this way the resulting prevalence figures are actually only a fraction of $1 \%$ of the global population in any given period using the lower estimate and only rise above $1 \%$ from the mid- $20^{\text {th }}$ Century at the higher estimate.

Ferri et al. (2005) arrived at consensus estimates for modern global dementia prevalence divided into $11 \mathrm{WHO}$ regions. The estimates in this study for the least developed regions compare interestingly with those from our own model with figures for North Africa and the Middle Eastern Crescent of 3.6\%, Indonesia, Sri Lanka and Thailand: 2.7\%, India and South Asia: 1.9\% and sub Saharan Africa $1.6 \%$. Again these rates would suggest the figures produced by our own model to be understated rather than the reverse. Lastly an obvious test of this approach would be to see what it tells us about modern prevalence. If this modelling approach works it should give at least a reasonably accurate idea of current global prevalence. Published estimates for current global dementia prevalence vary but tend to fall around 35 million (WHO, 2012; Prince et al. 2013). Our model gives lower and higher estimates of 25.7 and 30.0 million respectively which would appear reassuring in suggesting the model as a whole to be more likely underestimating than over estimating incidence and prevalence over time. 


\section{Discussion}

Whilst the model presented here has generated some very specific numbers, this was not the primary aim of this exercise. Rather the current study was intended to explore several issues at a very broad level and it is in this regard that the results generated are argued to be of value. There are three general conclusions which emerge from the simulation we have produced, the first of which concerns the proportion of past people likely to have lived to what would now be regarded as older age. Whilst there is no doubt that the average human lifespan is now longer than it has ever been and more people survive to a venerable age than ever before, a view that older individuals were a rarity at any time before the modern era (Blagosklonny, 2010; Marsh, 2014, Moody and Saunders, 2014, 301) is at odds with a broad variety of evidence. The model produced for the current study generates figures for the total numbers of individuals likely to have lived past 65 during recent millennia that run into billions. This is an important point as older people are a group that has received relatively little explicit consideration in studies of the past. Following a realization that the lives of women had previously been under-researched, the most recent group to come into better focus is the young with studies appearing during the last decade or so specifically focusing on evidence for children in the past (Crawford \& Shepherd, 2007). The current study underlines the case for now taking greater account of older people as having been both alive and contributing to past societies in greater numbers than is commonly accepted. We would argue that older people remain a group which has received disproportionately little attention in studies of the past and to whom it is logical to now extend the same consideration as other previously marginalised sections of society. Notable exceptions to this include the recently published studies by Cave \& Oxenham (2014) and Gowland (2015). The latter suggests bioarchaeological methods for identifying possible incidences of past elder abuse. This is particularly relevant to the current study given there is a higher than average prevalence of elder abuse among people with dementia (Cooper et al., 2008). With increasing awareness of older people in past societies, it is hoped there will be more studies to join these in the near future.

Secondly, our initial model has been used to estimate the numbers likely affected by a condition specifically associated with advancing age for which incidence and survival times are known with 
reasonable accuracy. Of course a thought experiment of this kind will have very large margins for error being dependent on a raft of necessarily broad assumptions. The method we have developed here is obviously open to criticism on this basis (as are all simulations). We were conscious of this from the outset and were under no illusions that it might be possible to arrive at figures that could be described as precise. Instead we aimed to arrive at a plausible suggestion based on explicit and reasonable assumptions for the likely overall order of magnitude of the occurrence of this condition in order to foster general conclusions regarding its likely impact on human societies over time. We would contend that the overall approach taken is sound in so far as it borrows an approach in current use for making forward predictions for global dementia prevalence. Where such modern projections for the future trajectory of dementia produce results at variance with each other these discrepancies are argued to relate to differences in assumptions and diagnostic criteria rather than in calculation methodology (Brookmeyer et al., 2011). In spite of these points the approach we have taken could still be criticised for being over simplistic and there are certainly aspects of the model that could be refined. For example survival times for modern people diagnosed with dementia aged less than 70 tend to be longer than for those diagnosed after 70 (Xie et al., 2008). These nuances could be specifically built into the model rather than glossed over as a single mean survival time as we have used. However, given the overall margin of error in the population estimates and the relative incidences we have used for past populations such a refinement would not produce final figures that could be regarded as substantively more accurate or useful. Our highly simplified view of human socioeconomic development could similarly be elaborated to take account of a range of more subtle definitions and differing levels of early industrialization. Again, this would present considerable challenges in terms of estimating the relative effects and proportions of each distinction in population numbers whilst doing nothing to reduce the overall margin of error in the final results. Such refinements would also leave the central conclusion of this study unaltered; that while the prevalence of dementia in past societies will have been less significant than in modern populations, it most certainly impacted numerous individuals and those who will have provided their care. Where population estimates exist for the likely size of particular settlements at a given date in the past it is possible to set this conclusion into a specific context. For example the population of Imperial Rome in 
the $1^{\text {st }}$ century AD has been plausibly estimated at around 450,000 (Storey, 1997), while the population of $14^{\text {th }}$ century London just prior to the Black Death has been estimated in the order of 80100,000 (Galloway \& Murphy, 1991). Assuming these populations represent those surviving beyond infancy, when the lifetime incidence rate in the current study $(1.81 \%)$ is modified by excluding those dying before their $5^{\text {th }}$ year the result is $2.16 \%$. Applying this rate to Rome and London at these dates would mean that in these cities 9,720 and 1,728 -2,160 inhabitants living at these respective times could expect to develop dementia during their lifetimes.

Lastly, a further implication of the current study is that the method presented here could be adapted and applied to other categories of chronic disease, although caution must be taken where past and modern ways of living diverge and exposure to relevant risk factors may have differed. Arguably the most important conclusion to emerge from the current study is that rather than being a new development which humans have not previously needed to cope with, the model presented here places dementia alongside a wide range of other challenges which have impacted human societies for thousands of years. If this is the case then a further conclusion would be that dementia is a trial that has so far been withstood successfully, on one hand at a proportionately lower incidence but on the other without the considerable clinical, technological and social advances that have been made in recent times, which we suggest is a cause for optimism as planners decide how best to face this continuing challenge in the future.

\section{References}

Alzheimer's Disease International. (2014). World Alzheimer Report. Dementia and Risk Reduction. An analysis of protective and modifiable factors. Available from:

http://www.alz.co.uk/research/world-report-2014 (accessed June 2014).

Alzheimer's Disease International (2008). The Prevalence of Dementia Worldwide. 2008. Available from: https://www.alz.co.uk/adi/pdf/prevalence.pdf (accessed June 2014). 
Alzheimer's Society (2014). Dementia UK Update Available from:

http://www.alzheimers.org.uk/dementiauk (accessed November 2014)

Banerjee, S. (2012). “The Macroeconomics of Dementia - Will the World Economy Get Alzheimer's Disease?" Archives of Medical Research, 43, 705-709.

Berchtold, N.C. \& Cotman, C.W. (1998). "Evolution in the conceptualization of dementia and Alzheimer's disease: Greco-Roman period to the 1960's" Neurobiology of Ageing, 19, 173-189.

Biraben, J.N. (1979). "Essai sur l'évolution du nombre des hommes" Population, 1, 13-25.

Biraben, J.N. (1980). “An Essay Concerning Mankind's Evolution” Population, Selected Papers

Blagosklonny, M.V. (2010). "Why human lifespan is rapidly increasing: solving "longevity riddle" with "revealed-slow-aging" hypothesis" Aging, 2, 177-182.

Bocquet-Appel, J.P. (2011). "When the World's population took off: the springboard of the Neolithic Demographic Transition” Science, 333, 560-561.

Brookmeyer, R., Evans, D.A., Hebert, L., Langad, K.M., Heeringaf, S.G., Plassmang, B.L. \& Kukull, W.A. (2011). "National estimates of the prevalence of Alzheimer's disease in the United States" Alzheimers and Dementia, 7, 61-73.

Brookmeyer R., Johnson E., Ziegler-Graham K. \& Arrighi H.M. (2007). "Forecasting the global burden of Alzheimer's disease" Alzheimers and Dementia, 3, 186-91. 
Catindig, J.S., Venketasubramanian, N., Kamram Ikram, M. \& Chen, C. (2012). "Epidemiology of dementia in Asia: Insights on prevalence, trends and novel risk factors" Journal of the Neurological Sciences, 321, 11-16.

Chamberlain, A. (2000). "Problems and prospects in palaeodemography" " in: Cox, M. \& Mays, S. (Eds.) Human Osteology in Archaeology and Forensic Science London: Greenwich Medical Media, $101-116$.

Cave, C. \& Oxeham, M. (2014). “Identification of the archaeological 'invisible elderly': an approach illustrated with an Anglo-Saxon example" International Journal of Osteoarchaeology, (Earlyview online).

Coale, A.J. \& Demeny, P. (1983). Regional Model Life Tables and Stable Populations, Second Edition, Princeton: Princeton University Press.

Colantuoni E., Surplus G., Hackman A., Arrighi H.M. \& Brookmeyer R. (2010). “Web-based application to project the burden of Alzheimer's disease" Alzheimers and Dementia, 6, 425-8.

Cooper, C., Selwood, A. \& Livingstone, G. (2008). "The prevalence of elder abuse and neglect: a systematic review" Age and Ageing, 37, 151-160.

Crawford, S. \& Shepherd, G. (2007). Children, Childhood and Society. IAA Interdisciplinary Series Vol. I: Studies in Archaeology, History, Literature and Art. B.A.R. International Series 1696. Oxford: Archaeopress.

Cutler, R. (1975). "Evolution of human longevity and the genetic complexity governing aging rate" Proceedings of the National Academy of Science of the United States of America, 72, 664-668.

http://mc.manuscriptcentral.com/jah 
Dickel, D.N. \& Doran, G.H. (1989). "Severe neural tube defect syndrome from the Early Archaic of Florida" American Journal of Physical Anthropology, 80, 325-334.

Durand, J.D. (1977). "Historical estimates of world population" Population and Development Review 3, 253-296.

Ferri, C., Prince, M., Brayne, C., Brodaty, H., Fratiglioni, L., Ganguli, M., Hall, K., Hasegawa, K., Hendrie, H., Huang, Y., Jorm, A., Mathers, C., Menezes, P., Rimmer, E. \& Scazufca, M. (2005).

"Global prevalence of dementia: a Delphi consensus study" The Lancet, 366, 2112-2117.

Galloway, J.A. \& Murphy, M. (1991). "Feeding the city: Medieval London and its agrarian hinterland" The London Journal, 16, 3-13.

Gènova-Maleras, R., lvarez-Martín, E.A., Morant-Ginestar, C., Fernández de Larrea-Baz, N. and Catalá-López, F. (2012). "Measuring the burden of disease and injury in Spain using disabilityadjusted life years: An updated and policy-oriented overview" Public Health, 126, 1024-1031.

Gottfried, R.S. (1983). The Black Death: Natural and Human Disaster in Medieval Europe New York: Free Press.

Gowland, R. L. (2015). "Elder Abuse: Evaluating the Potentials and the Problems of Diagnosis in the Archaeological Record” International Journal of Osteoarchaeology, (Earlyview online) DOI: 10.1002/oa.2442.

Gurven, M. \& Kaplan, H. (2007). “Longevity Among Hunter-Gatherers: A Cross-Cultural Examination" Population and Development Review, 33, 321-365. 
Haines, M.R. (1979). “The Use of Model Life Tables to Estimate Mortality for the United States in the Late Nineteenth Century" Demography, 16, 289-312.

Haley, W.E. \& Pardo, K.M. (1989). "Relationship of severity of dementia to caregiving stressors" Psychology and Aging, 4, 389-392.

Haub, C. (2011). How Many people Have Ever Lived on Earth? Washington: Population Reference Bureau (available from:

http://www.prb.org/Publications/Articles/2002/HowManyPeopleHaveEverLivedonEarth.aspx (accessed July 2014).

Hawkey, D.E. (1998). “Disability, compassion and the skeletal record: using musculoskeletal stress markers (MSM) to construct an osteobiography from Early New Mexico" International Journal of Osteoarchaeology 8, 326-340.

Henderson, S. \& Broe, G.A. (2010). "Dementia in Aboriginal Australians" Australia and New Zealand Journal of Psychiatry, 44, 869-871.

Hodkinson, S. (2002). "Social order and the conflict of values in classical Sparta" in: Whitby, M. (Ed.) Sparta Edinburgh: Edinburgh University, 104-131.

Hrdy, S. B. (2009). Mothers and Others: The Evolutionary Origins of Mutual Understanding. Cambridge: Harvard University Press.

Kalaria, R.N., Maestre, G.E., Arizaga, P., Friedland, R.P., Galasko, D., Hall, K., Luchsinger, J.A., Ogunniyi, A., Perry, E.K., Potocnik, F., Prince, M., Stewart, R., Wimo, A., Zhang, Z. \& Antuono, P. (2008). “Alzheimer's disease and vascular dementia in developing countries: prevalence, management, and risk factors" Lancet Neurology, 7, 812-826. 
Karenberg, A. \& Förstl, H. (2006). "Dementia in the Graeco-Roman world” Journal of the Neurological Sciences, 244, 5-9.

Kebric, R. (1988). “Old age, the ancient military and Alexander's army: positive examples for a graying America” The Gerontologist, 28, 298-302.

Lacey, R. \& Danziger, D. (1999). The Year 1000: What life was like at the turn of the Millennium London: Little, Brown and Company.

Livi-Bacci, M. (2007). A Concise History of World Population London: Wiley-Blackwell.

Luna, L.H., Aranda, C.M., Bosio, L.A. \& Beron, M.A. (2008) “A case of multiple metastasis in Late Holocene hunter-gatherers from the Argentine Pampean Region" International Journal of Osteoarchaeology 18, 492-506.

Marsh, H., (2014). “Growing old disgracefully: s deconstruction of death” New Statesman available from: http://www.newstatesman.com/books/2014/10/growing-old-disgracefully-deconstruction-death (accessed December 2014).

Matheson, B. (2005). "A farewell with arms: departing warriors on Athenian vases" in: Barringer, J.M. and Hurwit, J.M. (Eds.) Periklean Athens and its Legacy: Problems and Perspectives Austin (TX): University of Texas, 23-35.

McEvedy, C. \& Jones, R. (1978). "Atlas of World Population History" New York: Facts on File.

Metzler, I. (2013). A Social History of Disability in the Middle Ages London: Routledge. 
Midwinter, E. (2009). “The social history of older age” International Health, 1, 111-116.

Mitchell, A.J. \& Shiri-Feski, M. (2009). "Rate of progression of mild cognitive impairment to dementia: meta-analysis of 41 robust inception cohort studies" Acta Psychiatrica Scandinavica 119, $252-265$.

Moody, H.R. \& Saunders, J.R. (2014). Aging: Concepts and Controversies London: Sage.

Office for National Statistics (2007). UK Interim Life Tables 1982-2006 London: Government Actuary's Department.

Ottilingham, S. (2007). “The psychiatry of King Lear” Indian Journal of Psychiatry, 49, 52-55.

Pelletier, K.R. (1981). "Lifestyle and longevity: mind over matter" in: Dychtwald, K. (Ed.) Healthy Aging: Challenges and Solutions Gaithersburg (MA): Aspen publications, (pp. 333- ).

Porter, R. (1999). The Greatest Benefit to Mankind: A Medical History of Humanity from Antiquity to the Present. London: Fontana.

Prince, M., Prina, M. \& Guerchet, M. (2013). World Alzheimer Report 2013: Journey of Caring -an Analysis of Long-Term Care for Dementia London: Alzheimer's Disease International.

Ritchie, K., Kildea, D. \& Robine J. (1992) “The relationship between age and the prevalence of senile dementia: a meta-analysis of recent data" International Journal of Epidemiology, 21, 763-769.

Ritchie, K. \& Kildea, D. (1995). “Is senile dementia age-related or ageing related?” The Lancet, 346, 931-934.

Rocca, W.A., Petersen, R.C., Knopman, D.S., Hebert, L.E., Evans, D.A., Hall, K.S., Gao, S., Unverzagt, F.W., Langa, K.M., Larson, E.B. \& White, L.R. (2011). “Trends in the incidence and prevalence of Alzheimer's disease, dementia, and cognitive impairment in the United States" Alzheimer's and Dementia, 7, 80-93. 
Ruiz-Torres, A. \& Beier, W. (2005). “On maximum human life span: interdisciplinary approach about its limits" Advances in Gerontology, 16, 14-20.

Sandidge, M. (2007). "Forty years of plague: attitudes toward old age in the tales of Bocaccio and Chaucer" in: Classen, A. (Ed.) Old Age in the Middle Ages and the Renaissance: Interdisciplinary Approaches to a Neglected Topic New York: Walter de Gruyter (pp.357-373).

Schutkowski, H., Schultz, M. \& Holzgraefe, M. (1996). "Fatal Wounds in a Late Neolithic Double Inhumation-a Probable Case of Meningitis Following Trauma" International Journal of Osteoarchaeology, 6, 179-184.

Scott, R.A. (2010). Miracle Cures: Saints, Pilgrimage and the Healing Powers of Belief"' L.A: University of California.

Seshadri, S., Wolf, P.A., Beiser, A., Au, R., McNulty, K., White, R. \& D'Agostino R.B. (1997). "Lifetime risk of dementia and Alzheimer's disease: the impact of mortality on risk estimates in the Framingham Study" Neurology, 49, 1498-504.

Smith, K., Flicker, L., Dwyer, A., Atkinson, D., Almeida, O.P., Lautenschlager, N.P. \& LoGiudice, D. (2010) "Factors associated with dementia in Aboriginal Australians" Australian and New Zealand Journal of Psychiatry 44, 888-893.

Sterling, S. (1999). "Mortality Profiles as Indicators of Slowed Reproductive Rates: Evidence from Ancient Egypt” Journal of Anthropological Archaeology, 18, 319-343.

Storandt, M., Grant, E.A., Miller, J.P. \& Morris, J.C. (2002). "Rates of progression in mild cognitive Neurology 59, 1034-1041. 
Storey, G.R. (1997). “The population of ancient Rome” Antiquity, 71, 966-978.

Thomlinson, R. (1975). Demographic problems, controversy over population control Encino (CA): Dickenson.

Tilley, L. (2013). Towards a Bioarchaeology of Care: A contextualised approach for identifying and interpreting health-related care provision in prehistory. (Unpublished $\mathrm{PhD}$ Thesis, Australian National University).

Tilley, L. \& Oxenham, M.F. (2011). "Survival against the odds: Modelling the social implications of care provision to seriously disabled individuals" International Journal of Palaeopathology, 1, 35-42.

Trinkaus, E. \& Zimmerman, M.R. (1982). “Trauma among the Shanidar Neandertals” American Journal of Physical Anthropology, 57, 61-76.

United Nations (1973). The Determinants and Consequences of Population Trends Department of Economic and Social Affairs, Population Studies, 50.

United Nations Population Division (1999). The World at Six Billion available from: http://www.un.org/esa/population/publications/sixbillion/sixbillion.htmhttp://www.un.org/esa/populat ion/publications/sixbillion/sixbillion.htm (accessed July 2014).

U.S. Census Bureau (2012). Total Midyear Population for the World: 1950-2050 available from: http://www.census.gov/population/international/data/worldpop/table_population.php (accessed July 2014).

Waldron, T. (1994). Counting the Dead: the Epidemiology of Skeletal Populations. London: WileyBlackwell. 
Waldron, T. (1996). "What was the prevalence of malignant disease in the past" International Journal of Ostearchaeology 6, 463-470.

Waldron, T. (2007). Palaeoepidemiology: the Measure of Disease in the Human Past. Walnut Creek (CA), Left Coast Press.

Weiss, K. M. (1981). "Evolutionary perspectives on human aging” in P. Amoss and S. Harrell (Eds.) Other Ways of Growing Old. Stanford: Stanford University Press, pp. 25-28.

World Health Organisation (WHO). 2012. Dementia A public Health Priority. http://www.alz.co.uk/WHO-dementia-report

Xie, J., Brayne, C. \& Matthews, F.E. (2008). "Survival times in people with dementia: analysis from population based cohort study with 14 year follow-up" British Medical Journal, 336,258-264. 
Table 1: Example of progressive model life table equations - showing calculations for females within a population $(f)$.

\begin{tabular}{|c|c|c|c|c|c|c|c|c|}
\hline $\begin{array}{c}\text { Age } \\
\text { interval } \\
\text { cohorts } \\
x^{n}\end{array}$ & $\begin{array}{l}\text { Probability of } \\
\text { dying before } \\
\text { reaching } x^{n+1} \\
\text { (females) } \\
q^{f}(x)\end{array}$ & $\begin{array}{l}\text { Probability of } \\
\text { acquiring } \\
\text { dementia } \\
\text { before } \\
\text { reaching } x^{n+1} \\
\text { (females) } \\
k^{f}(x) \\
\end{array}$ & $\begin{array}{l}\text { Number of } \\
\text { individuals in } \\
\text { age interval } \\
\text { cohort } \\
n(x)\end{array}$ & $\begin{array}{l}\text { Number of total cases } \\
\text { of dementia in age } \\
\text { interval cohort } \\
I(k, x)\end{array}$ & $\begin{array}{l}\text { Number of non- } \\
\text { affected deaths in } \\
\text { age interval } \\
\text { cohort } \\
d(x)\end{array}$ & $\begin{array}{l}\text { Number of } \\
\text { dementia- } \\
\text { affected deaths } \\
\text { in age interval } \\
\text { cohort } \\
d(k, x)\end{array}$ & $\begin{array}{c}\text { Number of } \\
\text { survivors in age } \\
\text { interval cohort } \\
l(x)\end{array}$ & $\begin{array}{l}\text { Number of } \\
\text { dementia- } \\
\text { affected } \\
\text { survivors in age } \\
\text { interval cohort } \\
\qquad S(x)\end{array}$ \\
\hline $0-1$ & 0.2561 & 0.0 & $=\frac{\left[\left(\frac{N}{2}\right) \times B R\right]}{100}$ & $=P^{f}(x) n(x)$ & $\begin{array}{l}=q^{f}(x)[n(x)- \\
I(k, x)]\end{array}$ & $=q^{f}(x) I(k, x)$ & $\begin{array}{l}=n(x)-d(x)- \\
d(k, x)\end{array}$ & $\begin{array}{l}=I(k, x)- \\
d(k, x)\end{array}$ \\
\hline $1-4$ & 0.1779 & 0.0 & $=4 l\left(x^{n-1}\right)$ & $\begin{array}{l}=k^{f}(x)[n(x)- \\
\left.S\left(x^{n-1}\right)\right]+S\left(x^{n-1}\right)\end{array}$ & & & 2. & \\
\hline $5-9$ & 0.0502 & 0.0 & $\begin{array}{l}=l\left(x^{n-1}\right)+ \\
l\left(x^{n-2}\right)\end{array}$ & & & & & \\
\hline $10-14$ & 0.0393 & 0.0 & $=l\left(x^{n-1}\right)$ & 工 & & & & \\
\hline $15-19$ & 0.0513 & 0.0 & & 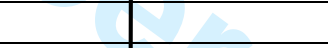 & & & & \\
\hline $20-24$ & 0.0640 & 0.0 & & & & & & \\
\hline $25-29$ & 0.0717 & 0.0 & & & & & & \\
\hline $30-34$ & 0.0808 & 0.0 & & 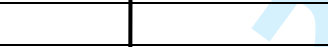 & & & & \\
\hline $35-39$ & 0.0885 & 0.0 & & & 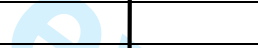 & & & \\
\hline $40-44$ & 0.0949 & 0.0 & & & +2 & & & \\
\hline $45-49$ & 0.1023 & 0.0 & & & 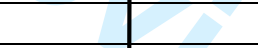 & & & \\
\hline $50-54$ & 0.1314 & 0.0 & & & & & & \\
\hline $55-59$ & 0.1659 & 0.0 & & & & & & \\
\hline $60-64$ & 0.2368 & 0.004 & & & & & & \\
\hline $65-69$ & 0.3086 & 0.010 & & & & & & \\
\hline $70-74$ & 0.4239 & 0.031 & & & & & & \\
\hline $75-79$ & 0.5574 & 0.060 & & & & & & \\
\hline $80-84$ & 0.6956 & 0.126 & & & & & & \\
\hline $85-89$ & 0.8375 & 0.202 & & & & & & \\
\hline $90-94$ & 0.9377 & 0.308 & & & & & & \\
\hline $95+$ & 1.0 & $0.308^{*}$ & $\downarrow$ & $\downarrow$ & $\downarrow$ & $\downarrow$ & $\downarrow$ & $\downarrow$ \\
\hline
\end{tabular}


The same equations used to calculate for females within a population $\left({ }^{f}\right)$ are also used to calculate for males within a population $(m)-$ see Appendix 3 for figures for $q\left(x^{m}\right)$ and $k\left(x^{m}\right)$; arrows indicate where equations repeat; in a static life table or the initial life table calculated for a progressive model $x^{1}=N_{0} \times y_{o}^{x}$

$B R=($ crude) birth rate; 4.0 (number of births per 1000 individuals in $N$ )

$N=$ population total (e.g. 10,000); $\sum_{n=0}^{\infty} n^{f}\left(x^{n}\right)+\sum_{n=0}^{\infty} n^{m}\left(x^{n}\right)$

$N_{0}=$ starting population (e.g. 10,000)

$y_{0}^{x}=$ percentage of $N_{0}$ at age interval cohort $x^{n}$; figures obtained from [38] representing a level 5 model west population.

$q(x)$ Figures obtained from Coale and Demeny (1983) representing a level 5 model west population.

$k(x)$ Figures obtained from Alzheimer's Disease International 2008 (see Table 2); * probabilities given up to $x^{n}=90+$

$P(x)$ Figures obtained from Alzheimer's Disease International 2008 (see Table 2); * probabilities given up to $x^{n}=90+$ 
Table 2. Modern age specific dementia incidence and prevalence rates (Alzheimer's Disease International, 2008).

\begin{tabular}{|l|c|c|c|c|c|c|}
\hline \multirow{2}{*}{ Age } & \multicolumn{2}{|c|}{ Annual Incidence per 100 $(k)$} & \multicolumn{3}{c|}{ Prevalence $(P)$} \\
\cline { 2 - 7 } & Males & Females & Mean & Males & Females & Mean \\
\hline $60-64$ & 0.2 & 0.2 & 0.2 & 0.4 & 0.4 & 0.4 \\
\hline $65-69$ & 0.2 & 0.3 & 0.25 & 1.6 & 1 & 1.3 \\
\hline $70-74$ & 0.6 & 0.5 & 0.55 & 2.9 & 3.1 & 3 \\
\hline $75-79$ & 1.4 & 1.8 & 1.6 & 5.6 & 6 & 5.8 \\
\hline $80-84$ & 2.8 & 3.4 & 3.1 & 11 & 12.6 & 11.8 \\
\hline $85-89$ & 3.9 & 5.4 & 4.65 & 12.8 & 20.2 & 16.5 \\
\hline $90+$ & 4.0 & 8.2 & 6.1 & 22.1 & 30.8 & 26.45 \\
\hline
\end{tabular}


Table 3. Calculation of total dementia (De) incidence over time as modelled by application of age specific dementia incidence rates modified by societal type to the results of the model outlined in Table 1 and the estimates of past world population published by Haub (2011). HG: Hunter Gatherer; R/P: Rural/preindustrial; M/D: Modern/developed; $d R$ : dementia incidence rate.

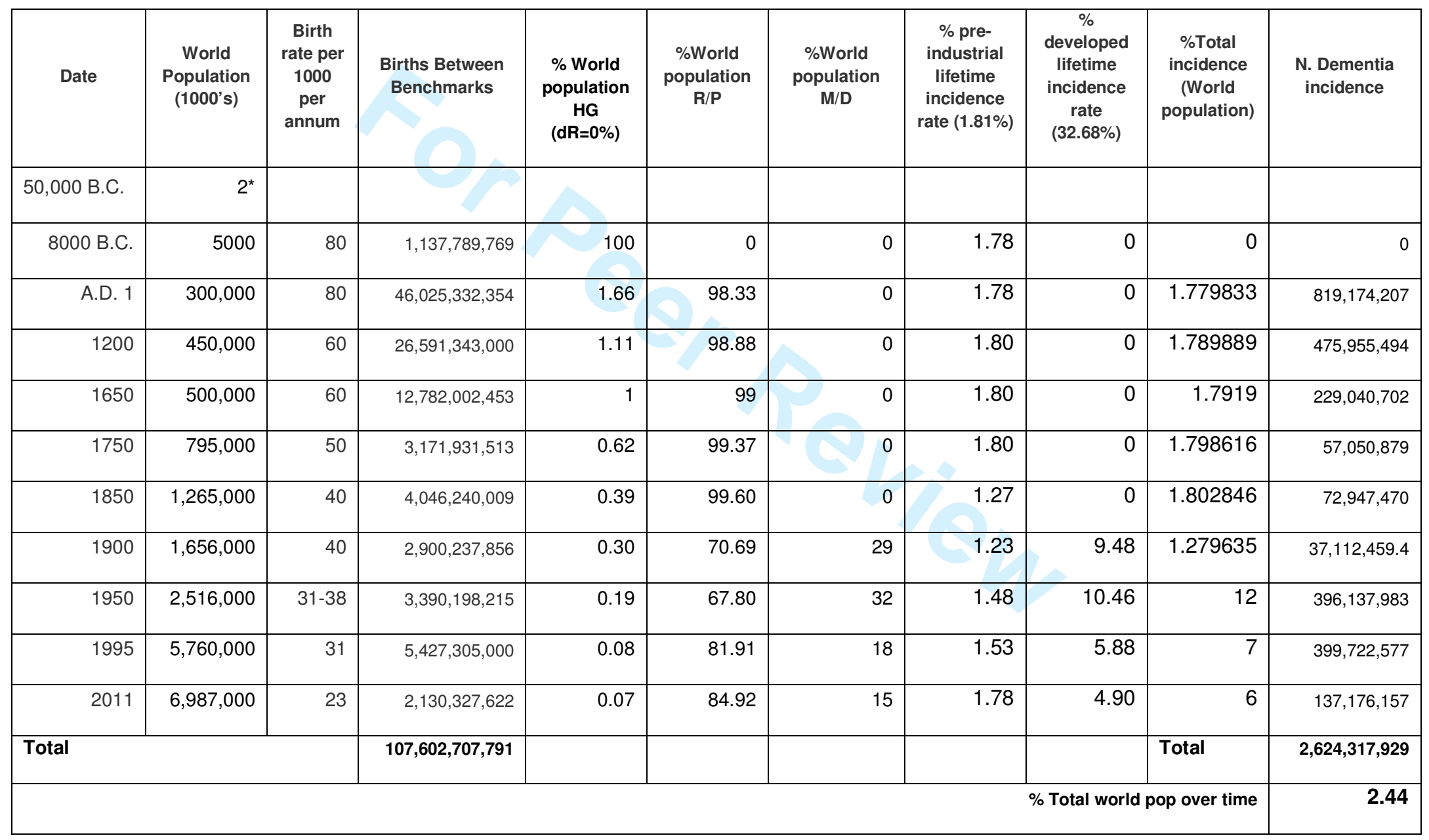




\section{Page 31 of 39}

Journal of Aging and Health

* Haub's (2011) figures use a mathematical model that starts with a small hypothetical population of 2000 during the Upper Palaeolithic -in reality the world's population at this time will have been considerably greater than this and is open to debate although this limitation of Haub's model has no overall impact on the later figures which accord with median values for a range of other published estimates.

http://mc.manuscriptcentral.com/jah 
Table 4. Global dementia prevalence over time as modelled by application of high and low survival time estimates to pre-industrial populations to the incidence figures in shown in Table 2. De: Dementia; Ide: Incidence of dementia.

\begin{tabular}{|c|c|c|c|c|c|c|c|c|}
\hline Date & $\begin{array}{l}\text { World } \\
\text { Population } \\
\text { (1000's) }\end{array}$ & $\begin{array}{l}\text { Births since last } \\
\text { interval }\end{array}$ & $\begin{array}{l}\text { IDe since last } \\
\text { interval }\end{array}$ & $\begin{array}{l}\text { Mean IDe per } \\
\text { year }\end{array}$ & $\begin{array}{l}\text { Mean N. De } \\
\text { alive (low } \\
\text { estimate) }\end{array}$ & $\begin{array}{l}\text { Mean N. De } \\
\text { alive (high } \\
\text { estimate) }\end{array}$ & $\begin{array}{l}\text { \% World } \\
\text { Prevalence } \\
\text { low estimate }\end{array}$ & $\begin{array}{l}\text { \% World } \\
\text { Prevalence } \\
\text { high estimate }\end{array}$ \\
\hline 8000 B.C. & 5000 & $1,137,789,769$ & 0 & 0 & 0 & 0 & 0 & 0 \\
\hline A.D. 1 & 300000 & $46,025,332,354$ & $819,174,207$ & $102,396.78$ & $204,793.55$ & $614,380.66$ & 0.07 & 0.20 \\
\hline 1200 & 450000 & $26,591,343,000$ & $475,955,494$ & $396,629.58$ & $793,259.16$ & $2,379,777.5$ & 0.18 & 0.53 \\
\hline 1650 & 500000 & $12,782,002,453$ & $229,040,702$ & $508,979.34$ & $101,7958.7$ & $3,053,876$ & 0.20 & 0.61 \\
\hline 1750 & 795000 & $3,171,931,513$ & $57,050,878.9$ & $570,508.79$ & $1,141,017.6$ & $3,423,052.7$ & 0.14 & 0.43 \\
\hline 1850 & 1265000 & $4,046,240,009$ & $72,947,470.1$ & $729,474.70$ & $1,458,949.4$ & $4,376,848.2$ & 0.11 & 0.35 \\
\hline 1900 & 1656000 & $2,900,237,856$ & $37,112,459.4$ & $742,249.19$ & $1,484,498.4$ & $4,453,495.1$ & 0.08 & 0.27 \\
\hline 1950 & 2516000 & $3,390,198,215$ & $396,137,983$ & $7,922,759.67$ & $15,845,519$ & $47,536,558$ & 0.63 & 1.89 \\
\hline 1995 & 5760000 & $5,427,305,000$ & $399,722,577$ & $8,882,723.94$ & $26,648,172$ & $93,268,601$ & 0.46 & 1.62 \\
\hline 2011 & 6987000 & $2,130,327,622$ & $137,176,157$ & $8,573,509.82$ & $25,720,529$ & $30,007,284$ & 0.37 & 0.43 \\
\hline
\end{tabular}




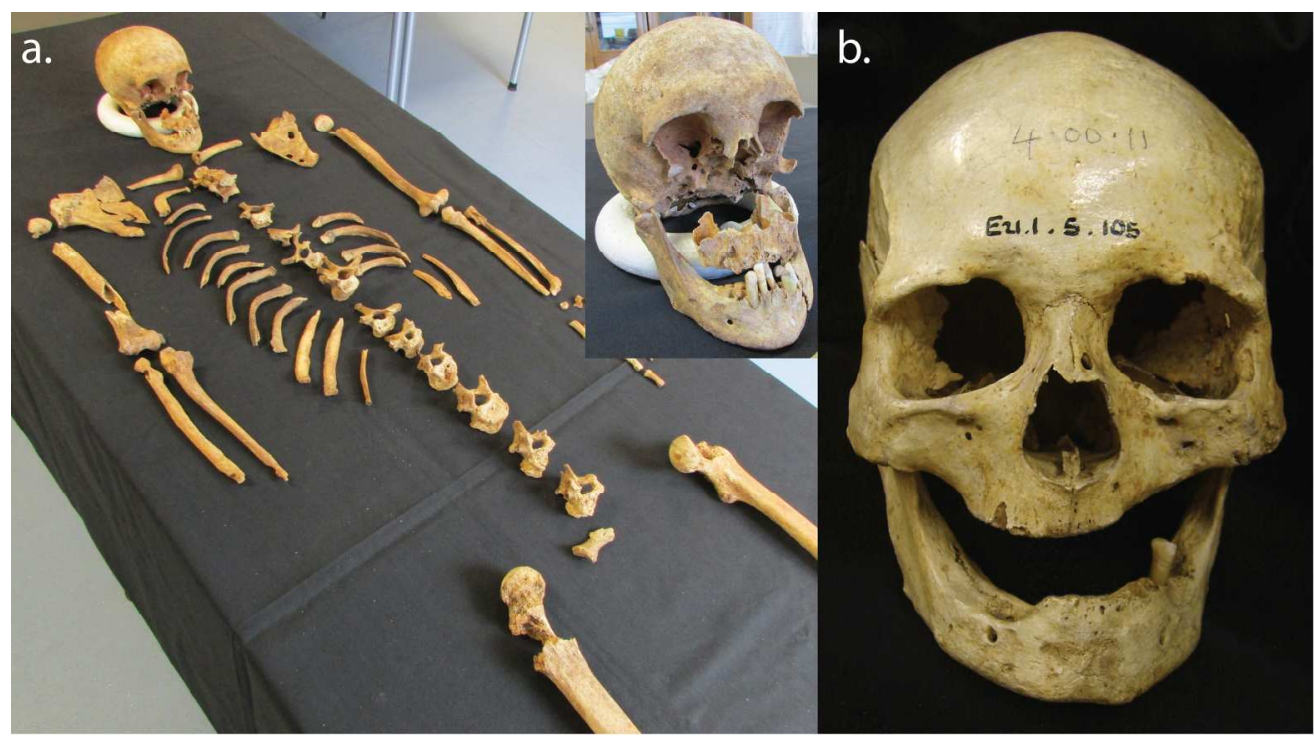

Figure 1a.) This skeleton excavated in Kingston-upon-Thames, England, was identified by a surviving brass coffin plate as the remains of Thomas Barnard who lived between 1675 and 1769 having survived to 94 . Using current osteological techniques this individual could only reliably be estimated as >55 years old from features of his skeleton, considerably masking his true age-at-death. b.) Skull of an older adult female from Lanhill Long Barrow (Wiltshire, England) dating from c.3600BC. This small, gracile individual had extensive arthritic changes and was almost toothless by the time of her death. It is unlikely she could have sustained herself independently in her later years without the support of others. $207 \times 114 \mathrm{~mm}(300 \times 300 \mathrm{DPI})$ 


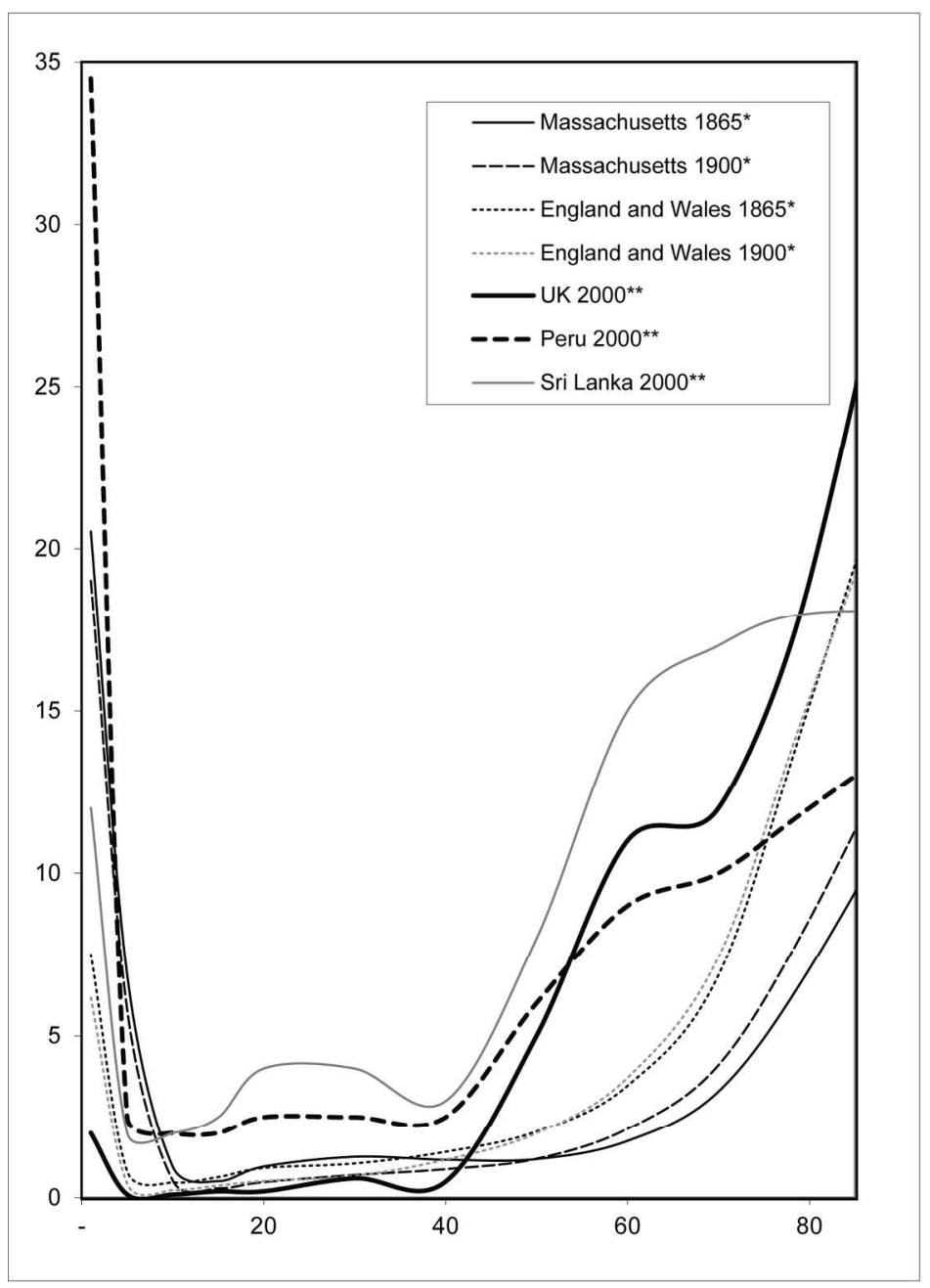

Figure 2. Percentage distribution by age of the total number of deaths in seven populations from differing dates and regions. In less developed societies (Peru, Sri Lanka and the two 19th century populations in this example) the curve assumes a more classic U-shape and is steeply angled on the left hand side reflecting high infant mortality. As societies become more developed the infant and child mortality rates drop and the right hand side of the curve becomes steeper as more deaths occur in old age. Importantly graphs of this

kind illustrate the misleading nature of 'mean age-at death' figures; in the less developed societies in particular the mean will be positioned somewhere near the centre of the graph despite the fact that very few deaths occur at ages in the middle of the range (sources: *Haines (1979), **Waldron (2007)). $145 \times 224 \mathrm{~mm}(300 \times 300 \mathrm{DPI})$ 
1

2

3

4

5

6

7

8

9

10

11

12

13

14

15

16

17

18

19

20

21

22

23

24

25

26

27

28

29

30

31

32

33

34

35

36

37

38

39

40

41

42

43

44

45

46

47

48

49

50

51

52

53

54

55

56

57

58

59

60

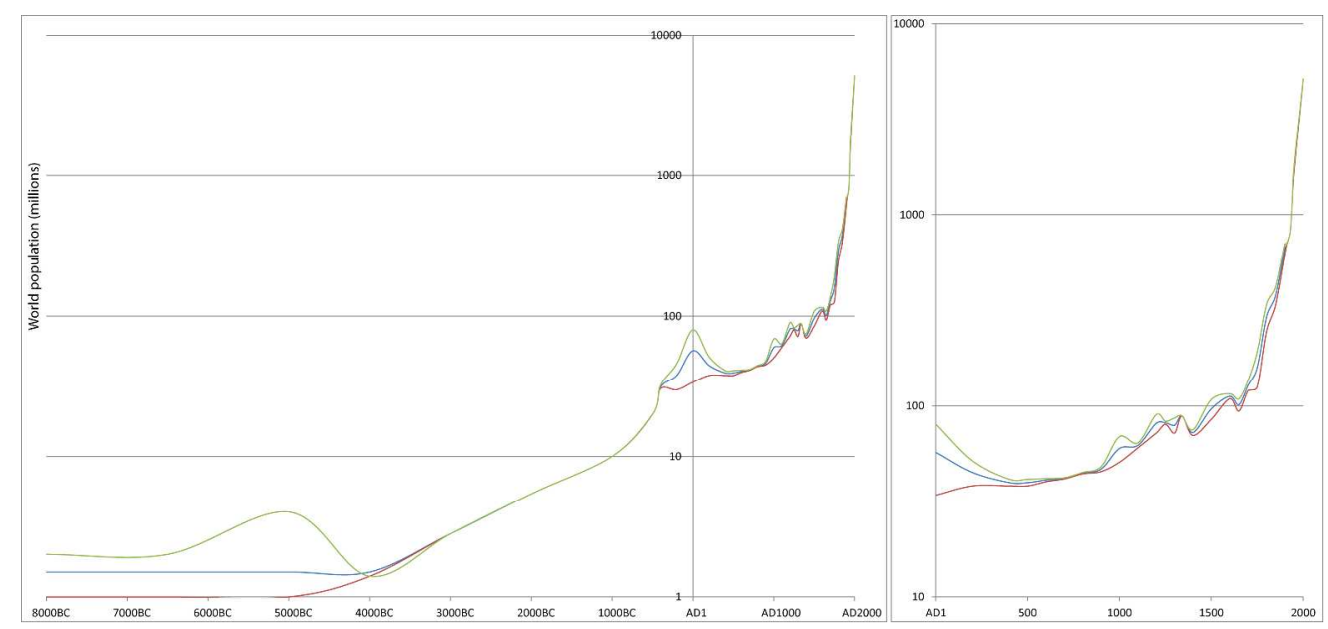

Figure 3. Summary of published estimates of the development of world population over the last 10,000 years. These are shown as a range with high, low and median estimates for each date used to produce continuous curves on a logarithmic scale (1,000,000's). Population was essentially stable at less than $10 \mathrm{~m}$. and grew only very slowly until the advent of farming and the NDT after which growth assumes an exponential rate which is further accelerated in the early modern/post medieval period (sources: Haub (2011); Livi-Bacci (2007); Biraben (1979, 1980); Durand (1977); McEvedy and Jones (1978); Thomlinson (1975); United Nations (1973); U.S. Census Bureau (2012); Midwinter (2009). $374 \times 174 \mathrm{~mm}(300 \times 300 \mathrm{DPI})$ 


\section{An age old problem? Estimating the impact of dementia on past human populations}

Martin J. Smith, Alison Atkin and Clare Cutler

\section{Appendices}

\section{Longevity in the past}

\subsection{Written sources}

Kebric's (1988) review of the literary and epigraphic evidence for Greece and Rome between 500BC and AD500 found over a thousand named individuals recorded as living beyond 60, with many reaching their $80 \mathrm{~s}$ and some living to even greater ages. Examples include Isocrates (Athenian orator 436-338 BC) who lived to 91, Heraclitus (Greek philosopher c.535-c.475 BC) who allegedly died at 96 and the mathematician Pythagoras (580-489 BC) who also survived to 91 (Pelletier, 1981, 333). In the classical world 60 was commonly regarded as the threshold of old age and the possibility of needing to be cared for in later life was one reason people were urged to have children (ibid.) In a similar vein the Roman Emperor Tiberius (42BC - AD37) issued an edict forbidding people from reproducing at over 60 on the basis that bringing up children would present too much of a challenge by this age and that parents might not live to see their offspring into adulthood. The salient point here is that this was a sufficiently common occurrence for such a proscription to be thought necessary. Furthermore, the ages at which one might be called upon for active military service in both Greece and Rome up to the $1^{\text {st }}$ century BC ranged from 18 to 60 (Matheson, 2005). Many examples are known of individuals remaining on active service past this age, whilst in Sparta 60 was the youngest age at which men were permitted to serve in government after relinquishing military duties [53]. Both literary allusions and contemporary records also demonstrate the presence of older individuals in the Medieval period. Sandidge $(2007,365)$ cites $30 \%$ of members of the House of Lords during the period 1350-1500 to have lived past 60 ; whilst in Tuscany $14.6 \%$ of the population were over 60 in 1427. One of several older characters in the Canterbury Tales, Chaucer's Knight has fought in battles 42 years apart leaving him close to 60 at the very youngest (ibid). In short, where older ages are mentioned in historical sources, it is in the general context of such survival being at least relatively common rather than a rare and unusual occurrence.

\section{2. 'Dead populations' - evidence from archaeological burials}

In a similar spirit to Chamberlain (2000) Cave and Oxenham (2014) demonstrate a method of seriating 'older' individuals within an Anglo Saxon cemetery population by paying careful attention to tooth wear and employing life table data from modern Hadza hunter-gatherers. Here "some $66 \%$ of the entire adult sample, originally allocated to the single final age category of $45+$ years, was distributed across four new age categories from the mid-40s to mid-70s". These are important studies as they demonstrate skeletal data to constitute reliable evidence that uniformitarian assumptions about the structure of past populations are broadly correct and also that model life table data derived from modern (or relatively recent) populations are broadly applicable to the past. In both cases these points lead to a conclusion that a substantive proportion of any human population would normally be expected to survive beyond 60 regardless of the period in which they lived. The concept of mortality profiles shifting in line with changes in economy and subsistence methods is also supported archaeologically. The most prominent example of such is a pronounced change in the composition of cemetery populations apparent throughout the world at the time of the birth of agriculture. Farming 
appears to have arisen independently in eight world regions between c.9,500BC and c.1,500 BC. The resultant change from mobile foraging to a settled, sedentary lifestyle, combined with the increased availability of high calorie foods in unprecedented volumes dramatically increased the numbers of people a given area of land could support whilst also reducing the viable interval between births as infants no longer needed to be habitually carried for long distances (Hrdy, 2009). As a consequence population sizes expanded dramatically, with this change, generally referred to as the Neolithic Demographic Transition (NDT), constituting one of the major demographic shifts in human history and one of the most important events to affect our species. Bocquet-Appel (2011) demonstrates that the NDT can be seen in archaeological cemetery populations throughout the world in the form of an abrupt increase in the proportions of 5-19 year olds coincident with the advent of agriculture. $\mathrm{He}$ suggests that "at the peak of the NDT there were children everywhere and the average age of the population was about 18 years old" (Bocquet-Appel, 2011). Without other factors taking effect this population explosion would have led to exponential growth, however these new ways of living also brought increased exposure to infectious disease which increased overall mortality so that demographic profiles soon took on a growth rate and mortality profile typical of pre-industrial farming populations observed in more recent times [56]. This point is further supported by a recent study by Fahlander (2013) who found $18 \%$ of the burials in a Middle Neolithic cemetery in Sweden to fall in the 'older adult' category. This would be consistent with $l 65$ rate of approximately $20 \%$ observed for preindustrial populations in general during more recent periods (Gurven and Kaplan, 2007). Conversely, Sterling (1999) demonstrates statistically significant differences in mortality profiles between skeletal samples from Predynastic and early Dynastic cemeteries from Ancient Egypt (pre and post c. 3000BC respectively). In this case whilst the former exhibit a profile that is skewed towards the younger age categories, the latter contain greater proportions of Middle and Older aged adults (usually categorised as individuals aged 35-50 and 50+). This change is coincident with the introduction of more efficient, collectively irrigated agriculture and the emergence of civilization, and would be consistent with the notion that Egyptian society became capable of supporting greater numbers of older individuals from this point onwards.

\subsection{A window to the past? The ethnographic present}

Palaeolithic humans (before 8,000 BC) have previously been claimed to have had a mean life expectancy of only 15-20 years, increasing to 25 years with the birth of agriculture (Cutler, 1975, Weiss, 1981). Prior to the development of agriculture (during the Neolithic) all human societies lived by hunting and gathering and for the last 10,000 years we have no reason to think that conditions were any less favourable than they have been recently. In fact the opposite is probably true in that modern hunter gatherers have often been forced to live in marginal environments unfavourable to settled farming whereas in the past they would have lived in considerably richer surroundings where survival was easier. In considering previously published prehistoric life tables Gurven and Kaplan (2007) note that these estimates show greater differences between modern and prehistoric hunter gatherers than have been shown between modern hunter gatherers and wild chimpanzees in their own study. They conclude that such tables can therefore be regarded as overly pessimistic stemming probably from systematic biases and inaccurate estimates. Also if such profiles represented genuine past mortality with so few people reaching old age this would raise the question of how the human life course as it now exists had ever evolved at all?

\section{Dementia in the historical record}

The earliest acknowledged mention of symptoms consistent with dementia is contained in an Egyptian text from the $24^{\text {th }}$ century BC. Here an elderly court official (Ptah-Hotep) is described as spending 
"every night becoming more childish" and whose "heart is exhausted and fails to remember yesterday" (Karenberg and Förstl, 2006, 7). Clear references to dementia in old age are later found in the writings of a range of classical authors, the earliest of whom, Pythagoras, dates from the $7^{\text {th }}$ century BC. This text divides the human life course into four stages during the last of which "the system returns to the imbecility of the first epoch of infancy" (cited in Berchtold and Cotman, 1998, 173). Whilst Pythagoras claimed this was an age to which "fortunately very few of the human species survives" (ibid.) the inclusion of consideration of loss of mental capacity in old age in Athenian law codes of the following century would indicate that such loss of faculties was sufficiently common to be taken seriously by those in government (Berchtold and Cotman, 1998, 173). A deterioration of mental faculties was also mentioned by Hippocratic writers in the 4th century BC and elaborated on by Plato and Aristotle (Karenberg and Förstl, 2006, 6). Virgil (70-19BC) is famously quoted for noting that "Age carries away all things, even the mind" (Eclogues IX, 51). With characteristic insight, and in tones that accord well with modern ideas on the subject, the Roman author and orator Cicero (106-43BC) viewed elderly mental decline as something that could specifically be averted or at least delayed by maintaining an active and engaging life. Three centuries later the Roman physician Galen (c. AD 150-200) described "morosis" as a condition that could occur in various circumstances including old age [39] specifically noting memory loss as an important component. Karenberg and Förstl (2006) cite a broad range of authors of medical, philosophic and literary texts that span the classical period through to the $3^{\text {rd }}$ century $\mathrm{AD}$ who give repeated descriptions of symptoms consistent with modern observations of Alzheimer's disease (A.D.), vascular dementia (VaD.) and other kinds of dementia, noting that the overall prevalence of these mentions would therefore seem to reflect the "prevalence of such observations and concerns in real-life". In fact the use of the term "senile" to denote demented individuals rather than its original meaning "aged" is likely to have had its roots in the writings of this period (Berchtold and Cotman, 1998, 175). Classical thinking remained the guiding principle in European medicine until the renaissance (Porter, 1999). Little further thought appears to have been given to dementia up to this time, probably as it was regarded as an inevitable feature of ageing rather than a pathological condition that might be preventable or treatable. However, literary references, particularly by Chaucer and Shakespeare (Ottilingham, 2007) again confirm that senile dementia (as distinct from other forms of mental illness) remained prevalent enough to be both generally recognised and considered worth mentioning. 
3. Figures of $q\left(x^{m}\right)$ and $k\left(x^{m}\right)$

\begin{tabular}{|c|c|c|}
\hline $\begin{array}{l}\text { Age interval } \\
\text { Cohorts } x^{n}\end{array}$ & $\begin{array}{l}\text { Probability of dying } \\
\text { before reaching } x^{n+1} \\
\text { (males) } q\left(x^{m}\right)\end{array}$ & $\begin{array}{l}\text { Probability of acquiring } \\
\text { dementia before reaching } \\
x^{n+1} \text { (males) } k\left(x^{m}\right)\end{array}$ \\
\hline $0-1$ & 0.2959 & 0.0 \\
\hline $1-4$ & 0.1774 & 0.0 \\
\hline $5-9$ & 0.0470 & 0.0 \\
\hline $10-14$ & 0.0338 & 0.0 \\
\hline $15-19$ & 0.0460 & 0.0 \\
\hline $20-24$ & 0.0653 & 0.0 \\
\hline $25-29$ & 0.0729 & 0.0 \\
\hline $30-34$ & 0.0840 & 0.0 \\
\hline $35-39$ & 0.0982 & 0.0 \\
\hline $40-44$ & 0.1180 & 0.0 \\
\hline $45-49$ & 0.1364 & 0.0 \\
\hline $50-54$ & 0.1708 & 0.0 \\
\hline $55-59$ & 0.2063 & 0.0 \\
\hline $60-64$ & 0.2737 & 0.004 \\
\hline $65-69$ & 0.3522 & 0.016 \\
\hline $70-74$ & 0.4597 & 0.029 \\
\hline $75-79$ & 0.6007 & 0.056 \\
\hline $80-84$ & 0.7268 & 0.11 \\
\hline $85-89$ & 0.8573 & 0.128 \\
\hline $90-94$ & 0.9462 & 0.221 \\
\hline $95+$ & 1.0 & $0.221 *$ \\
\hline
\end{tabular}

http://mc.manuscriptcentral.com/jah 